\title{
Tranexamic Acid Update in Trauma
}

\author{
Ricardo J. Ramirez, MD, Philip C. Spinella, MD, Grant V. Bochicchio, MD, MPH* \\ Washington University in St. Louis School of Medicine, St Louis, MO, USA
}

Ricardo J. Ramirez, MD, Department of Surgery, Washington University School of Medicine; ramirezr@wudosis.wustl.edu

Philip C. Spinella, MD, Department of Pediatrics, Washington University School of Medicine; spinella p@kids.wustl.edu

Lena M. Napolitano, MD

*Corresponding author: Grant V. Bochicchio, MD, MPH, Department of Surgery, Washington University School of Medicine, 660 South Euclid Avenue, CB 8109, St Louis, MO 63110; bochicchiog@wudosis.wustl.edu

\section{Tranexamic acid, Trauma, Coagulopathy, Hemorrhage, Antifibrinolytics, Surgery}

\begin{abstract}
Following results from the CRASH-2 trial, tranexamic acid (TXA) gained considerable interest for the treatment of hemorrhage in trauma patients. Although TXA has been shown to be effective at reducing mortality in bleeding trauma patients presenting within three hours of injury, optimal dosing, timing of administration, mechanism, and pharmacokinetics in trauma patients require further elucidation. Moreover, the recent concept of fibrinolysis shutdown in hemorrhagic trauma patients has prompted discussion of real time viscoelastic testing and its potential role for appropriate patient selection. The results of ongoing clinical trials will help establish high quality evidence for optimal incorporation of TXA in mature trauma networks in both the United States and abroad.
\end{abstract}




\section{Key Points}

- Tranexamic acid, a synthetic lysine derivative, has previously shown efficacy for reducing blood loss in a number of surgical procedures.

- TXA has shown a mortality benefit in bleeding trauma patients when administered within three hours of injury, however not a decrease in blood product transfusions.

- Pharmacokinetics and optimal dosing in trauma patients remain unknown.

- Ongoing and future trials are needed to refine current understanding of TXA's mechanisms of action in trauma patients and to optimize drug administration.

\section{Introduction}

Trauma is the leading cause of death and disability worldwide, with an estimated 5.8 million people dying every year as a result of traumatic injury $[1,2]$. In both military and civilian settings, hemorrhage remains the most common cause of preventable death after traumatic injury [3-6]. In recent years, there has been considerable interest in antifibrinolytic agents for the prevention of hemorrhagic death in severe trauma patients. The CRASH-2 and MATTERs studies were pivotal, landmark studies that brought the antifibrinolytic agent tranexamic acid (TXA) to the forefront of discussion after evidence suggested improved mortality in civilian and military trauma respectively [7, 8]. Based on results from the CRASH-2 trial, in March of 2011, TXA was added to the World Health Organization's list of essential medications. Yet, widespread adoption by mature trauma systems in the United States has been slow due to concerns about unknown exact mechanism of action, uncertainty surrounding use in patients with concomitant traumatic brain injury (TBI), unknown precise pharmacokinetics in the trauma patient, and safety [9-11]. The results of these two landmark studies sparked worldwide debate and prompted funding for a number of trials to address these and other concerns [12-18]. 
This review provides a brief overview of the history of TXA, reviews the known and proposed mechanisms of action, and examines areas of ongoing and future research aimed at addressing unanswered questions.

\section{Background}

TXA is a synthetic lysine derivative that exerts its action by competitively occupying the lysine binding site of plasminogen, thereby blocking interaction with fibrin and subsequent clot breakdown [19]. TXA has a molecular weight of $157.2 \mathrm{~g} / \mathrm{mol}$, and its injectable formulation is marketed under the name Cyklokapron. The pharmacokinetics of TXA in healthy individuals after administration of a $10 \mathrm{mg} / \mathrm{kg}$ dose demonstrate peak concentrations at 60 minutes postadministration, with a half-life of approximately 2 hours for the terminal elimination phase, and $90 \%$ excretion at 24 hours. An antifibrinolytic dose remains in tissues for up to 17 hours and in serum for up to eight hours. It has also been shown to cross the placental barrier, is excreted in breast milk, and rapidly appears in synovial fluids [20]. The pharmacokinetics in trauma patients may differ however, and appropriate dosing in this population may not be reflective of clinically effective concentrations previously described in healthy individuals. Pharmacokinetics and effects of TXA on hemostasis and immune systems are currently subjects of large ongoing trials with US Government funding $[12,13,15]$.

In 1986, the FDA approved intravenous administration of TXA for the indication of prevention or reduction of bleeding in patients with hemophilia undergoing dental procedures. The oral form of TXA, marketed under the brand name Lysteda, was approved by the FDA in 2009 to control heavy menstrual bleeding [21]. The drug has also been widely studied for the reduction of bleeding in cardiopulmonary bypass (CPB) surgery [22-29], and orthopedic procedures [30] including its applicability in spine [31], knee [32], and shoulder surgery [33]. In 
the 1990 's and early 2000 's, the antiinflammatory properties of antifibrinolytics were recognized in patients undergoing CPB surgery, and in 2007 Jimenez et al. published a manuscript confirming this observation [26]. The same year, Brohi et al. described the protein C pathway and its important role in the development of coagulopathy and hyperfibrinolysis following trauma [34]. This important work gave rise to new interest in antifibrinolytics and their effects on the intimate relationship that exists between inflammatory and coagulation pathways.

A 2012 meta-analysis of surgical studies evaluating TXA, included 129 trials (1972 through 2011)with 10,488 patients mostly in elective surgical procedures, the majority for cardiac surgery. Pooled results from 95 trials evaluating risk of blood product transfusion demonstrated that TXA had a 38\% risk reduction of perioperative blood product administration (pooled relative risk (RR), $0.62 ; 95 \%$ confidence interval $(\mathrm{Cl}), 0.58-0.65 ; p=0.001$ ). With adequate allocation concealment, 32 trials showed similar results (pooled RR, 0.68; 95\% Cl, 0.62-0.74; $p=0.001$ ), and the same was true of 69 trials with adequate blinding (pooled $R R, 0.63 ; 95 \% \mathrm{Cl}$, 0.59-0.68; $p=0.001)$. When analyzing the effect of TXA on death, they found that fewer deaths occurred in the TXA group ( $R R 0.61,95 \% \mathrm{Cl} 0.38-0.98 ; \mathrm{p}=0.04$ ). However, when evaluating only those studies with adequate concealment, there was uncertainty ( $\mathrm{RR} \mathrm{0.67,} \mathrm{Cl} 0.33-1.34$; $p=0.25)$. Their analysis of TXA's effect on thromboembolic events also yielded inconclusive results [35].

\section{CRASH-2}

The Clinical Randomization of an Antifibrinolytic in Significant Hemorrhage (CRASH-2) trial was a randomized placebo controlled trial carried out in 274 hospitals in 40 countries that evaluated the effects of TXA in 20,211 adult trauma patients who had significant bleeding or 
were at risk for significant bleeding [8]. The design of the study was pragmatic and enrollment in the study was dependent on whether a responsible doctor was "substantially uncertain about whether or not to treat with TXA". In other words, those patients that had either a clear indication or contraindication for administration of antifibrinolytics were excluded. Patients arriving within 8 hours of injury were randomly assigned to receive a 1 gram bolus over 10 minutes followed by a 1 gram infusion over 8 hours, or matching placebo. Primary outcome was death in hospital within 4 weeks of injury. The study reported a reduction in all-cause mortality in the treatment group (14.5\%) vs. the placebo group (16.0\%); RR 0.91; 95\% Cl, 0.85-0.97; $(p=0.0035)$. A reduction in the risk of death due to bleeding was also reported ( $4.9 \%$ vs $5.7 \%) ; R R$ $0.85 ; 95 \% \mathrm{Cl}, 0.76-0.96 ;(p=0.0077)$. Vascular occlusive events including $\mathrm{MI}$, stroke, DVT, and pulmonary embolism were similar in both groups. There was no significant difference in number of transfusions, need for surgery, or amount of blood products transfused, and baseline demographics for each group were similar [8]. In post hoc analysis, it was confirmed that early treatment with TXA was most effective. Patients for whom the drug was started within 1 hour of injury had the greatest benefit, with nearly a one-third reduction in risk of death due to bleeding (RR 0.68; 95\% Cl, 0.57-0.82; $\mathrm{p}<0.0001$ ). Treatment started between 1 and 3 hours from time of injury also had reduced risk ( $\mathrm{RR} 0.79 ; 95 \% \mathrm{Cl}, 0.64-0.97 ; \mathrm{p}=0.03$ ). However, treatment that was started after 3 hours increased the risk of death from bleeding (RR 1.44; 95\% Cl, 1.12-1.84; $p=0.004)$ [36]. It was estimated that the odds ratio (OR) of TXA on death due to bleeding is multiplied by 1.15 (95\% Cl 1.08-1.23) for every hour that passes from the time of injury (Figure 1) [36].

Fig.1 Effect of TXA on mortality due to bleeding, by time from injury to treatment in hours. From Roberts I, et al: The importance of early treatment with tranexamic acid in bleeding trauma patients: an exploratory analysis of the CRASH-2 randomised controlled trial. Lancet 2011, 377(9771):1096-1101, 1101.e1091-1092]; with permission. 
CRASH-2 is the largest randomized controlled trial ever conducted for trauma, and was the first to demonstrate a mortality benefit recommending TXA use in bleeding trauma patients. However, the results of CRASH-2 are controversial and a number of groups have questioned the applicability in countries with mature trauma networks $[9,10,18]$. For example, a large number of the patients were treated in facilities with limited resources, including availability of blood products early on. Furthermore, data concerning burden of injury and quantification of blood loss were lacking, and there was no protocolized approach for the detection and/or diagnosis of thromboembolic events. The trial also left a number of questions unanswered, such as mechanisms by which the drug reduces mortality in bleeding trauma patients. CRASH-2 investigators attempted to address some of these concerns offering several explanations [37]. They argued that large pragmatic study designs are able to yield results that are reflective of everyday clinical practice, and that one of the inherent limitations of such a design is the inability to offer physiological explanations. Another question arose regarding the seemingly absent effect of TXA on number of blood products transfused. Roberts et al. offered the explanation of survivor bias, meaning that those patients who received TXA were more likely to survive and thus had a greater opportunity to receive more blood products [38]. The authors admitted that the rate of nonfatal vascular occlusive events were potentially underreported due to limited access and the lack of routine screening for this [8]. In addition to the controversy in peer-reviewed journals, the study was widely debated online in blogs, medical forums, and other social media [18].

More recently, a number of smaller cohort studies integrating TXA in mature trauma systems in the United States have failed to produce favorable results, only further fueling the debate [39-41]. A prospective study in a severely injured civilian cohort within a mature civilian 
trauma system documented that TXA was not independently associated with any change in outcome for the overall trauma cohort or for non-shock patients. In multivariate analysis, TXA was protective for adjusted all-cause mortality (OR $0.16, \mathrm{Cl} 0.03-0.86, \mathrm{p}=0.03$ ) in severely injured hemorrhagic shock patients.

\section{MATTERs}

The Military Application of Tranexamic Acid in Trauma Emergency Resuscitation (MATTERs) study was a retrospective observational study that evaluated the effects of TXA in patients with combat related injury that received at least one unit of packed red blood cells. All patients were treated in a military surgical hospital at Camp Bastion, in southern Afghanistan. They evaluated 896 consecutive admissions with mortality at 24 and 48 hours, and in-hospital mortality at 30 days as their primary endpoints. Secondary endpoints included TXA's effect on transfusion requirements, measures of coagulopathy and thromboembolic events. The TXA group was found to have an unadjusted in-hospital mortality of $17.4 \%$ vs. $23.9 \%$ in the no-TXA group ( $p=0.03$ ), despite the TXA group being more severely injured (ISS 25.2 vs. 22.5, respectively). In patients that received massive transfusion, defined as $\geq 10$ units of packed red blood cells (PRBCs) in a 24 hour period, the associated reduction in mortality was even more significant (14.4\% in TXA vs. 28.1\% in no-TXA ; $p=0.004)$. TXA was also independently associated with greater survival $(\mathrm{OR}=7.228 ; 95 \% \mathrm{Cl}, 3.016-17.322)$ and less coagulopathy $(\mathrm{p}=.003)$ [7]. In contrast to the CRASH-2 study however, the MATTERs study reported an associated increased risk of thromboembolic events in the TXA patients, but felt that this greater risk was attributed to the higher injury severity in the TXA patients. However, when evaluated by multivariate analysis, adjusting for severity of injury, no independent association between TXA use and thromboembolic events was found. The authors still acknowledged that TXA poses a theoretical 
increased risk of thromboembolic occurrences and should therefore be kept in mind when designing future prospective studies [7].

\section{Patient Evaluation Overview}

\section{The Role of Fibrinolysis in Trauma}

Acute Traumatic Coagulopathy (ATC) develops in the presence of tissue injury and shock due to bleeding, and has been shown to be present in up to $25 \%$ of trauma patients upon arrival to the emergency department (ED) [42]. ATC is a primary or endogenous cause of coagulopathy associated with increased activated protein C, and is the result of the body's biologic response to traumatic injury [43]. It is characterized by dysfibrinogenemia, hyperfibrinolysis, endothelial dysfunction, and impaired platelet activity [44]. Unbalanced resuscitation is an iatrogenic or secondary cause of coagulopathy with hemodilution, hypothermia, and acidosis contributing to exacerbation of hemostatic dysfunction [43, 44] (Figure 2).

Fig.2 Pathophysiology of coagulopathy following trauma

From: [Davenport RA, Brohi K: Cause of trauma-induced coagulopathy. Curr Opin Anaesthesiol 2016, 29(2):212-219]; with permission.

Fibrinolysis has been shown to be an important pathophysiological component of coagulopathy developing from trauma, and hyperfibrinolysis (HF) is a significant contributor to mortality in trauma patients [34, 44-47]. Many studies have reaffirmed the integral role of fibrinolysis in the pathogenesis of ATC $[45,48]$. However, some have cautioned against the generalized use of antifibrinolytic agents such as TXA in all trauma patients due to new evidence that suggests reduced fibrinolytic activity, or "fibrinolysis shutdown" in up to $46 \%$ of severely injured patients [49]. In this retrospective study, Moore et al. very recently published evidence 
for the possibility of three distinct fibrinolytic phenotypes: shutdown, physiologic, and hyperfibrinolysis. Using their thromboelastography (TEG) databank, they evaluated trauma patients $>18$ years, with an ISS $>15$, presenting to the ED between 2010 and 2013 . A total of 2,540 patients were included. They grouped patients by lysis measurement 30 minutes after maximum amplitude (LY30, \%) defining shutdown, physiologic, and hyperfibrinolysis with LY30 values of $\leq 0.8 \%, 0.9 \%-2.9 \%$, and $\geq 3 \%$ respectively. Fibrinolysis shutdown was the most common phenotype (46\%), followed by physiologic (36\%), and hyperfibrinolysis (18\%). Hyperfibrinolysis accounted for the highest mortality with $34 \%$, shutdown $22 \%$, and physiologic 14\%. After adjusting for age, ISS, mechanism, head injury, and blood pressure, risk of mortality remained increased for hyperfibrinolysis (OR 3.3; 95\% Cl, 2.4-4.6; $p<0.0001$ ) and shutdown (OR 1.6; $95 \% \mathrm{Cl}, 1.3-2.1 ; \mathrm{p}=0.0003$ ) compared with physiologic (OR $0.82 ; 95 \% \mathrm{Cl}, 0.80-0.84)$ [49]. The leading cause of death for the hyperfibrinolysis phenotype was due to acute blood loss, while $40 \%$ of patients displaying LY30 consistent with shutdown phenotype died of multiple organ failure. Moore et al. have proposed possible mechanisms for microvascular occlusion following fibrinolysis shutdown in severely injured patients [50]. However, their theories have not been demonstrated in vivo, and critics of this theory have pointed out that many patients who might have otherwise benefited from early administration of TXA, might miss out due to wait times for TEG results for lysis [51].

\section{Proposed Mechanisms of Action in Trauma}

The antifibrinolytic effect of TXA is exerted through competitive inhibition of plasmin formation. This occurs when TXA binds to lysine binding domains exposed on plasminogen, resulting in diminished plasmin levels, thereby preventing clot lysis. However, some authors have suggested that this may not be the sole mechanism of action responsible for increased survival in trauma patients $[9,10]$. The coagulation cascade, contrary to what was routinely 
taught to many of us in medical school, it is not a simple series of events occurring in a predictable chain of molecular interactions. Rather, coagulation and fibrinolysis are complex pathways influenced by many other complex pathways including: complement, cytokines, endothelium, and cellular immune systems $[52,53]$.

Before the year 2007, aprotinin was used extensively in CPB surgery for its antiplasmin properties [29]. Ultimately, aprotinin was withdrawn from the market due to safety concerns after publication of the BART study [54]. However, before the drug was withdrawn, investigators took note of its effect on the inflammatory response present in patients undergoing CPB surgery $[26,55]$. After 2007 , the drug was quickly replaced by TXA, which had previously shown similar efficacy for reducing blood loss and risk of postoperative transfusion, without increased risk in MI, stroke, or death [56]. Subsequent recognition of similar effects of TXA have led to increasing interest in the antiinflammatory and potential immunomodulatory mechanisms of TXA $[26,53]$. As a result, these parallel mechanisms are the subject of multiple ongoing trials around the world $[12,13,15]$

\section{TXA use in children}

TXA use in children has been studied in a variety of surgical settings and has been shown to be effective at reducing blood loss for orthopedic, cardiac, and craniofacial surgeries $[25,57-$ 59]. Based on results of the CRASH-2 trial, and that of an observational pediatric study that showed an association with increased survival with TXA use in trauma, some advocate for its use in children $[60,61]$. Although TXA has been studied extensively in the adult trauma patient, less evidence exists for children, and its use in the pediatric trauma population is not as widespread. A study using a large administrative dataset from 36 U.S. children's hospitals found that in all instances in which TXA was used (a total of 35,478 records), only 110 encounters $(0.31 \%)$ were 
found to have been for trauma. The majority of patients that received TXA were in patients undergoing cardiac surgery $(22,863 ; 64 \%)$ [62]. A single retrospective cohort study of 766 injured children in Afghanistan reported that TXA was only used in $10 \%$ of pediatric trauma admissions, although its administration was independently associated with a $27 \%$ reduction in mortality $(p=0.03)[60]$. In a survey study of US and Canadian pediatric hospitals., antifibrinolytics (TXA and/or aminocaproic acid), were reported to be incorporated in $15 \%$ of MTPs [63]. Like adults, early coagulopathy and shock were independent predictors of mortality in children with traumatic injuries who were treated at combat support hospitals in Iraq and Afghanistan. Coagulopathy was present on admission in $27 \%$ of the children, and a higher injury severity score predicted increased coagulopathy, shock, and mortality [64]. When TXA is used in pediatric trauma, some centers are using a dose range of $25-50 \mathrm{mg} / \mathrm{kg}$ IV bolus (maximum 2 grams) with or without a $10 \mathrm{mg} / \mathrm{kg}$ infusion over 8 hours. Therefore, to our knowledge, there is no data in children to guide TXA administration.

\section{Pharmacologic Treatment Options}

\section{Contraindications}

TXA is contraindicated in those who have hypersensitivity to the drug and ongoing acute vascular occlusion or thrombosis. Relative contraindications include history or risk factors predisposing to thromboembolic events. TXA use in patients with macroscopic hematuria poses risk of development of clot obstructions in the ureters and has been reported to cause acute renal cortical necrosis with oliguria and renal failure [19]. Subarachnoid hemorrhage (SAH) is also considered to be a contraindication by some [65], but others advocate for its use in this population [66].

\section{Dosing in Trauma}


Several TXA dosing regimens for use in traumatic hemorrhage have been described

(Table 1). The dosing regimen that was selected for the CRASH-2 trial was based on previous

studies carried out in surgical patients [8]. Early studies in this population, demonstrated that a dose of $10 \mathrm{mg} / \mathrm{kg}$ followed by $1 \mathrm{mg} / \mathrm{kg} / \mathrm{h}$ decreased bleeding during cardiac surgery and larger doses did not incur greater benefit for preventing blood loss $[67,68]$. Because TXA has a large therapeutic range, researchers selected the empirical dose of a 1 gram bolus followed by a 1 gram infusion over 8 hours, to provide adequate plasma levels for patients over $100 \mathrm{~kg}$ while remaining safe for patients weighing less than $50 \mathrm{~kg}$ [19]. The meta-analysis by Ker et al. also suggested that a dose of $1 \mathrm{~g}$ produced a reduction in bleeding in the surgical patients with no evidence to support higher doses in this population [35]. Although in the trauma patient, it is possible that larger doses could have a greater treatment effect. Ongoing studies will further elucidate pharmacokinetics of TXA in the trauma patient and help to determine appropriate dose [13].

Table 1. Dosing Regimens for Traumatic Hemorrhage

\begin{tabular}{|l|l|l|}
\hline Study & Dose & Indication \\
\hline CRASH-2 [8] & $\begin{array}{l}\text { 1 gram bolus followed } \\
\text { by a 1 gram infusion } \\
\text { over 8 hours }\end{array}$ & $\begin{array}{l}\text { Adult trauma patients with significant hemorrhage } \\
\text { (SBP }<90 \mathrm{~mm} \mathrm{Hg} \text { or heart rate }>110 \mathrm{bpm} \text {, or both), } \\
\text { or who were considered to be at risk of significant } \\
\text { hemorrhage, and who were within } 8 \text { h of injury }\end{array}$ \\
\hline MATTERs [7] & $\begin{array}{l}\text { 1 gram bolus repeated } \\
\text { at discretion of treating } \\
\text { surgeon }\end{array}$ & $\begin{array}{l}\text { Patients who received at least 1 unit of PRBCs } \\
\text { within } 24 \text { hours of admission following combat } \\
\text { related injury }\end{array}$ \\
\hline TAMPITI [13] & $\begin{array}{l}\text { *Ongoing trial: one time } \\
\text { bolus of 2 or 4 grams }\end{array}$ & $\begin{array}{l}\text { Adult trauma patients ordered to receive at least 1 } \\
\text { blood product and/or immediate transfer to } \\
\text { operating room to control bleeding, and within 2 } \\
\text { hours of injury }\end{array}$ \\
\hline STAAMP [12] & $\begin{array}{l}\text { *Ongoing trial: one time } \\
\text { bolus of 1 gram }\end{array}$ & $\begin{array}{l}\text { Adult trauma patients being transported via air } \\
\text { medical services from scene or referring hospital, }\end{array}$ \\
\hline
\end{tabular}




\begin{tabular}{|l|l|l|}
\hline & prehospital dose & $\begin{array}{l}\text { with SBP }<90 \mathrm{~mm} \mathrm{Hg} \text { or heart rate }>110 \mathrm{bpm} \text {, and } \\
\text { within 2 hours of injury }\end{array}$ \\
\hline PATCH [69] & $\begin{array}{l}\text { *Ongoing trial: 1 gram } \\
\text { prehospital bolus } \\
\text { followed by 1 gram in- } \\
\text { hospital infusion over 8 } \\
\text { hours }\end{array}$ & $\begin{array}{l}\text { Adult trauma patients being transported to a } \\
\text { trauma center with a coagulopathy of severe } \\
\text { trauma (COAST) score of 3 or greater, and within 3 } \\
\text { hours of injury }\end{array}$ \\
\hline
\end{tabular}

It has been postulated by some, that most of TXA's benefit may come from the initial

bolus. If ongoing studies are able to provide evidence for administration of bolus alone, without the use of bolus plus infusion, it may promote wider adoption of TXA protocols. One study found that one of the barriers to widespread use of TXA at their institution was the complexity of administration [70].

\section{Damage Control Resuscitation and Prehospital Management of Hemorrhage}

Remote damage control resuscitation (RDCR) is the prehospital application of the basic concepts of DCR, and has been of recent interest in the military setting where early intervention is lifesaving $[43,71]$. Up to $25 \%$ of combat related injuries are considered to be potentially survivable, with hemorrhage being the cause of death in $90 \%[5,72,73]$. Currently, TXA may be the best pharmacologic option for prehospital hemostatic interventions, and its administration in the field has been shown to be feasible in both civilian and military settings $[3,74]$. Prehospital administration of TXA is still controversial, and currently enrolling trials will provide high level evidence regarding its efficacy and safety.

TXA may be considered in the prehospital setting as one component of care in a "bundle of therapies" [75]. In Canada, a team of first responders decided to integrate prehospital TXA as part of their MTP for hemorrhagic shock in civilian, primary, and secondary air medical evacuation [76]. They reported no inflight complications in their cohort of 13 patients over a 4 month period. The average time to TXA administration was 32 minutes ( $95 \% \mathrm{Cl}, 25.76-39.99)$. Another Canadian group, in a retrospective study, reported on 20 consecutive patients receiving 
TXA during helicopter transportation over a three year period. The median time in minutes from the time of injury to helicopter arrival, drug administration, and receiving hospital arrival was 90, 114, and 171 minutes, respectively, for calls to the scene [77]. Lipsky et al. reported that TXA administration caused no delay in evacuation of 40 consecutive patients treated in the military setting [78].

Certain considerations should be made when integrating the use of TXA in the prehospital setting including pharmacokinetics in trauma patients, storage under field conditions, and potential interactions with other RDCR drugs. Civilian and military personnel administering TXA as part of RDCR should also be trained in management of potential complications such as seizures or thrombosis under the field conditions [79]. The Study of Tranexamic Acid during Air Medical Prehospital transport (STAAMP) and the Pre-hospital Antifibrinolytics for Traumatic Coagulopathy and Hemorrhage (PATCH) studies are ongoing randomized controlled trials that will help to address these concerns $[12,15]$.

\section{Role of Viscoelastic Testing and Massive Transfusion Protocols}

Some authors have advocated for viscoelastic testing prior to administration of TXA due to concern for deleterious effects of TXA in a particular subset of patients $[50,80]$. Others have argued that viscoelastic tests of coagulation (TEG/ROTEM) may not be sufficiently sensitive, and that delay in drug administration while awaiting these labs will negatively impact patient outcomes $[48,51]$.

Although TXA use is not universally accepted in the United States, its integration in massive transfusion protocols (MTPs) is not uncommon. In a national survey of Level I and Level II ACS-TQIP designated trauma centers, 50\% (65 of 129) of respondents reported incorporation of an antifibrinolytic in their MTPs [81]. The same survey reported low incorporation of point-of- 
care TEG into MTPs. Identifying the patient in need of MTP activation remains challenging. Although a number of algorithms have been developed, and in light of less than optimal use of TEG, accurate predictors are still needed for identifying patients that will require MTP [82].

\section{Treatment Complications}

There is some concern for seizure with higher doses of TXA, and studies demonstrating causal effect have been in patients that received considerably large amounts. Indeed, up to 10 times higher than the dose used in CRASH-2 [27]. Mechanisms of seizure are still poorly understood but past studies have shown cerebral blood flow disturbances and inhibition of gamma-aminobutyric acid receptors [10]. TXA readily crosses the blood brain barrier and has been demonstrated in CSF in absence of TBI [22]. TXA is structurally similar to glycine and has also been shown to be a competitive inhibitor of glycine receptors in mice [83]. It is likely that this leads to neuronal hyperexcitability and diminished seizure threshold.

There have been a number of studies evaluating TXA in patients with SAH. In these studies, TXA was shown to reduce bleeding but was also associated with increased cerebral ischemia, hypothetically due to vasospasm or increased microvascular thrombosis [65]. However, because the treatment with TXA in some of the earlier studies was based on the prolonged dosing regimens in patients with hemophilia, these findings may be due in part to the effects of substantially larger doses [21]. A smaller study evaluating outcomes based on shortterm treatment produced encouraging results with trends towards improved mortality and no increase of ischemic stroke [84]. The uncertainty currently surrounding the efficacy of TXA for treatment of SAH is the subject of a large multicenter, randomized, placebo-controlled trial currently being conducted in Australia [66]. The results of this trial will hopefully shed light on the drug's utility for this indication. 


\section{Areas of Ongoing Research}

Currently there are three ongoing randomized controlled trials in the United States being funded by the US Department of Defense.

- $\quad$ STAAMP (Study of Tranexamic Acid during Air Medical Prehospital Transport) is a multicenter, randomized controlled trial to determine the effect of prehospital TXA infusion during air medical transport on 30-day mortality in patients at risk of traumatic hemorrhage. The trial will also explore the effects of TXA on the coagulation and inflammatory response following injury [12].

- $\quad$ TAMPITI (Tranexamic Acid Mechanisms and Pharmacokinetics in Traumatic Injury) is a randomized placebo controlled trial to evaluate the effects of TXA on the immune system, its pharmacokinetics, as well as safety and efficacy in severely injured trauma patients [13].

- Prehospital Tranexamic Acid Use for Traumatic Brain Injury Trial is a randomized control trial to determine the efficacy of two dosing regimens of TXA initiated in the prehospital setting in patients with moderate to severe TBI [85].

Additionally, there are a number of other ongoing trials evaluating TXA for other indications. The WOMAN (World Maternal Antifibrinolytic) trial is currently underway to evaluate TXA for the treatment and prevention of postpartum hemorrhage [16]. HALT-IT is a randomized controlled trial which will determine the effect of TXA in patients with acute gastrointestinal bleeding [17]. CRASH-3 is an international randomized controlled trial to quantify the effects of the early administration of TXA on death and disability in patients with traumatic brain injury[14]. 


\section{Summary}

The positive results of the CRASH-2 trial sparked both enthusiasm and controversy regarding the use of antifibrinolytics for patients with traumatic bleeding. As a result, a number of high quality RCTs are currently underway to help further elucidate utility of TXA and other antifibrinolytics in traumatic injury as well as other conditions with severe bleeding. In addition to awaiting the results of ongoing trials addressing the utility of TXA in the prehospital setting, effects on the immune system, and pharmacokinetics in trauma, the new concept of fibrinolysis shutdown has generated much interest and intrigue. This recently introduced theory would have significant implications for the use of TXA in trauma patients if proven in randomized controlled trials. Over the next few years, we expect to have a much better understanding of TXA and its utility, indications, and appropriate dosing. Based on the current evidence in the literature, we feel that TXA is appropriate in massive transfusion situations empirically for patients presenting within 3 hours of injury, but should be goal-directed in non-MTP situations. Further trials are needed to refine and optimize TXA dosing regimens.

\section{References}

\section{Uncategorized References}

1. Ker K, Kiriya J, Perel P, Edwards P, Shakur H, Roberts I: Avoidable mortality from giving tranexamic acid to bleeding trauma patients: an estimation based on WHO mortality data, a systematic literature review and data from the CRASH-2 trial. BMC Emerg Med 2012, 12:3.

2. Injuries and violence: the facts. Geneva, World Health Organization, 2010. Available at: [http://www.who.int/violence_injury_prevention/key_facts/en/]. Accessed April 28, 2016.

3. Nadler R, Gendler S, Benov A, Strugo R, Abramovich A, Glassberg E: Tranexamic acid at the point of injury: the Israeli combined civilian and military experience. J Trauma Acute Care Surg 2014, 77(3 Suppl 2):S146-150.

4. Frith D, Brohi K: The acute coagulopathy of trauma shock: clinical relevance. Surgeon 2010, 8(3):159-163. 
5. Eastridge BJ, Mabry RL, Seguin P, Cantrell J, Tops T, Uribe P, Mallett O, Zubko T, Oetjen-Gerdes L, Rasmussen TE et al: Death on the battlefield (2001-2011): implications for the future of combat casualty care. J Trauma Acute Care Surg 2012, 73(6 Suppl 5):S431-437.

6. Evans JA, van Wessem KJ, McDougall D, Lee KA, Lyons T, Balogh ZJ: Epidemiology of traumatic deaths: comprehensive population-based assessment. World J Surg 2010, 34(1):158-163.

7. Morrison JJ, Dubose JJ, Rasmussen TE, Midwinter MJ: Military Application of Tranexamic Acid in Trauma Emergency Resuscitation (MATTERs) Study. Arch Surg 2012, 147(2):113-119.

8. Shakur H, Roberts I, Bautista R, Caballero J, Coats T, Dewan Y, El-Sayed H, Gogichaishvili T, Gupta S, Herrera $\mathrm{J}$ et al: Effects of tranexamic acid on death, vascular occlusive events, and blood transfusion in trauma patients with significant haemorrhage (CRASH-2): a randomised, placebo-controlled trial. Lancet (London, England) 2010, 376(9734):23-32.

9. Napolitano LM, Cohen MJ, Cotton BA, Schreiber MA, Moore EE: Tranexamic acid in trauma: how should we use it? J Trauma Acute Care Surg 2013, 74(6):1575-1586.

10. Pusateri AE, Weiskopf RB, Bebarta V, Butler F, Cestero RF, Chaudry IH, Deal V, Dorlac WC, Gerhardt RT, Given MB et al: Tranexamic acid and trauma: current status and knowledge gaps with recommended research priorities. Shock 2013, 39(2):121-126.

11. Cole E, Davenport R, Willett K, Brohi K: Tranexamic acid use in severely injured civilian patients and the effects on outcomes: a prospective cohort study. Ann Surg 2015, 261(2):390-394.

12. Brown JB, Neal MD, Guyette FX, Peitzman AB, Billiar TR, Zuckerbraun BS, Sperry JL: Design of the Study of Tranexamic Acid during Air Medical Prehospital Transport (STAAMP) Trial: Addressing the Knowledge Gaps. Prehosp Emerg Care 2015, 19(1):79-86.

13. Spinella PC, Bochicchio GV:Tranexamic Acid Mechanisms and Pharmacokinetics In Traumatic Injury (TAMPITI Trial). Available at: [http://www.tampiti.wustl.edu/]. Accessed April 16, 2016.

14. Dewan Y, Komolafe EO, Mejia-Mantilla JH, Perel P, Roberts I, Shakur H: CRASH-3 - tranexamic acid for the treatment of significant traumatic brain injury: study protocol for an international randomized, double-blind, placebo-controlled trial. Trials 2012, 13:87.

15. Gruen RL, Jacobs IG, Reade MC: Trauma and tranexamic acid. The Medical journal of Australia 2013, 199(5):310-311.

16. Shakur H, Elbourne D, Gulmezoglu M, Alfirevic Z, Ronsmans C, Allen E, Roberts I: The WOMAN Trial (World Maternal Antifibrinolytic Trial): tranexamic acid for the treatment of postpartum haemorrhage: an international randomised, double blind placebo controlled trial. Trials 2010, 11:40.

17. Roberts I, Coats T, Edwards P, Gilmore I, Jairath V, Ker K, Manno D, Shakur H, Stanworth S, Veitch A: HALT-IT--tranexamic acid for the treatment of 
gastrointestinal bleeding: study protocol for a randomised controlled trial. Trials 2014, 15:450.

18. Binz S, McCollester J, Thomas S, Miller J, Pohlman T, Waxman D, Shariff F, Tracy R, Walsh M: CRASH-2 Study of Tranexamic Acid to Treat Bleeding in Trauma Patients: A Controversy Fueled by Science and Social Media. J Blood Transfus 2015, 2015:874920.

19. Tengborn L, Blomback M, Berntorp E: Tranexamic acid--an old drug still going strong and making a revival. Thromb Res 2015, 135(2):231-242.

20. CYKLOKAPRON- tranexamic acid injection, solution Pharmacia and Upjohn Company. Available at: [http://labeling.pfizer.com/ShowLabeling.aspx?id=556]. Accessed April 20, 2016.

21. Cap AP, Baer DG, Orman JA, Aden J, Ryan K, Blackbourne LH: Tranexamic acid for trauma patients: a critical review of the literature. $J$ Trauma 2011, 71(1 Suppl):S9-14.

22. Abou-Diwan C, Sniecinski RM, Szlam F, Ritchie JC, Rhea JM, Tanaka KA, Molinaro RJ: Plasma and cerebral spinal fluid tranexamic acid quantitation in cardiopulmonary bypass patients. J Chromatogr B Analyt Technol Biomed Life Sci 2011, 879(7-8):553-556.

23. Bernet F, Carrel T, Marbet G, Skarvan K, Stulz P: Reduction of blood loss and transfusion requirements after coronary artery bypass grafting: similar efficacy of tranexamic acid and aprotinin in aspirin-treated patients. Journal of cardiac surgery 1999, 14(2):92-97.

24. Bokesch PM, Szabo G, Wojdyga R, Grocott HP, Smith PK, Mazer CD, Vetticaden $\mathrm{S}$, Wheeler $\mathrm{A}$, Levy $\mathrm{JH}$ : A phase 2 prospective, randomized, double-blind trial comparing the effects of tranexamic acid with ecallantide on blood loss from high-risk cardiac surgery with cardiopulmonary bypass (CONSERV-2 Trial). J Thorac Cardiovasc Surg 2012, 143(5):1022-1029.

25. Couturier R, Rubatti M, Credico C, Louvain-Quintard V, Anerkian V, Doubine S, Vasse M, Grassin-Delyle S: Continuous or discontinuous tranexamic acid effectively inhibits fibrinolysis in children undergoing cardiac surgery with cardiopulmonary bypass. Blood Coagul Fibrinolysis 2014, 25(3):259-265.

26. Jimenez JJ, Iribarren JL, Lorente L, Rodriguez JM, Hernandez D, Nassar I, Perez $\mathrm{R}$, Brouard M, Milena A, Martinez R et al: Tranexamic acid attenuates inflammatory response in cardiopulmonary bypass surgery through blockade of fibrinolysis: a case control study followed by a randomized double-blind controlled trial. Crit Care 2007, 11(6):R117.

27. Kalavrouziotis D, Voisine P, Mohammadi S, Dionne S, Dagenais F: High-dose tranexamic acid is an independent predictor of early seizure after cardiopulmonary bypass. Ann Thorac Surg 2012, 93(1):148-154.

28. Karski JM, Teasdale SJ, Norman P, Carroll J, VanKessel K, Wong P, Glynn MFX: Prevention of bleeding after cardiopulmonary bypass with high-dose tranexamic acid: Double-blind, randomized clinical trial. The Journal of Thoracic and Cardiovascular Surgery 1995, 110(3):835-842.

29. Royston D: The current place of aprotinin in the management of bleeding. Anaesthesia 2015, 70 Suppl 1:46-49, e17. 
30. Jennings JD, Solarz MK, Haydel C: Application of Tranexamic Acid in Trauma and Orthopedic Surgery. Orthop Clin North Am 2016, 47(1):137-143.

31. Tsutsumimoto T, Shimogata M, Ohta H, Yui M, Yoda I, Misawa H: Tranexamic acid reduces perioperative blood loss in cervical laminoplasty: a prospective randomized study. Spine (Phila Pa 1976) 2011, 36(23):1913-1918.

32. Sabatini L, Atzori F, Revello S, Scotti L, Debiasi F, Masse A: Intravenous use of tranexamic acid reduces postoperative blood loss in total knee arthroplasty. Arch Orthop Trauma Surg 2014, 134(11):1609-1614.

33. Gillespie R, Shishani Y, Joseph S, Streit JJ, Gobezie R: Neer Award 2015: A randomized, prospective evaluation on the effectiveness of tranexamic acid in reducing blood loss after total shoulder arthroplasty. J Shoulder Elbow Surg 2015, 24(11):1679-1684.

34. Brohi K, Cohen MJ, Ganter MT, Matthay MA, Mackersie RC, Pittet JF: Acute traumatic coagulopathy: initiated by hypoperfusion: modulated through the protein C pathway? Ann Surg 2007, 245(5):812-818.

35. Ker K, Edwards P, Perel P, Shakur H, Roberts I: Effect of tranexamic acid on surgical bleeding: systematic review and cumulative meta-analysis. $B M J$ 2012, 344:e3054.

36. Roberts I, Shakur H, Afolabi A, Brohi K, Coats T, Dewan Y, Gando S, Guyatt G, Hunt BJ, Morales $\mathrm{C}$ et al: The importance of early treatment with tranexamic acid in bleeding trauma patients: an exploratory analysis of the CRASH-2 randomised controlled trial. Lancet (London, England) 2011, 377(9771):10961101, 1101.e1091-1092.

37. Roberts I, Shakur H, Coats T, Hunt B, Balogun E, Barnetson L, Cook L, Kawahara T, Perel P, Prieto-Merino D et al: The CRASH-2 trial: a randomised controlled trial and economic evaluation of the effects of tranexamic acid on death, vascular occlusive events and transfusion requirement in bleeding trauma patients. Health Technol Assess 2013, 17(10):1-79.

38. Roberts I: Tranexamic acid in trauma: how should we use it? J Thromb Haemost 2015, 13 Suppl 1:S195-199.

39. Harvin JA, Peirce CA, Mims MM, Hudson JA, Podbielski JM, Wade CE, Holcomb JB, Cotton BA: The impact of tranexamic acid on mortality in injured patients with hyperfibrinolysis. J Trauma Acute Care Surg 2015, 78(5):905-909; discussion 909-911.

40. Moore HB, Moore EE, Gonzalez E, Chapman MP, Chin TL, Silliman CC, Banerjee A, Sauaia A: Hyperfibrinolysis, physiologic fibrinolysis, and fibrinolysis shutdown: the spectrum of postinjury fibrinolysis and relevance to antifibrinolytic therapy. J Trauma Acute Care Surg 2014, 77(6):811-817; discussion 817.

41. Valle EJ, Allen CJ, Van Haren RM, Jouria JM, Li H, Livingstone AS, Namias N, Schulman CI, Proctor KG: Do all trauma patients benefit from tranexamic acid? J Trauma Acute Care Surg 2014, 76(6):1373-1378.

42. Brohi K, Singh J, Heron M, Coats T: Acute traumatic coagulopathy. J Trauma 2003, 54(6):1127-1130.

43. Jenkins DH, Rappold JF, Badloe JF, Berseus O, Blackbourne L, Brohi KH, Butler FK, Cap AP, Cohen MJ, Davenport R et al: Trauma hemostasis and 
oxygenation research position paper on remote damage control resuscitation: definitions, current practice, and knowledge gaps. Shock 2014, 41 Suppl 1:312.

44. Davenport RA, Brohi K: Cause of trauma-induced coagulopathy. Curr Opin Anaesthesiol 2016, 29(2):212-219.

45. Brohi K, Cohen MJ, Ganter MT, Schultz MJ, Levi M, Mackersie RC, Pittet JF: Acute coagulopathy of trauma: hypoperfusion induces systemic anticoagulation and hyperfibrinolysis. J Trauma 2008, 64(5):1211-1217; discussion 1217.

46. Dirkmann D, Radu-Berlemann J, Gorlinger K, Peters J: Recombinant tissue-type plasminogen activator-evoked hyperfibrinolysis is enhanced by acidosis and inhibited by hypothermia but still can be blocked by tranexamic acid. $J$ Trauma Acute Care Surg 2013, 74(2):482-488.

47. Frith D, Davenport R, Brohi K: Acute traumatic coagulopathy. Curr Opin Anaesthesiol 2012, 25(2):229-234.

48. Raza I, Davenport R, Rourke C, Platton S, Manson J, Spoors C, Khan S, De'Ath HD, Allard S, Hart DP et al: The incidence and magnitude of fibrinolytic activation in trauma patients. J Thromb Haemost 2013, 11(2):307-314.

49. Moore HB, Moore EE, Liras IN, Gonzalez E, Harvin JA, Holcomb JB, Sauaia A, Cotton BA: Acute Fibrinolysis Shutdown after Injury Occurs Frequently and Increases Mortality: A Multicenter Evaluation of 2,540 Severely Injured Patients. J Am Coll Surg 2016, 222(4):347-355.

50. Moore EE, Moore HB, Gonzalez E, Sauaia A, Banerjee A, Silliman CC: Rationale for the selective administration of tranexamic acid to inhibit fibrinolysis in the severely injured patient. Transfusion 2016, 56 Suppl 2:S110-114.

51. Roberts I: Fibrinolytic shutdown: fascinating theory but randomized controlled trial data are needed. Transfusion 2016, 56 Suppl 2:S115-118.

52. Laffey JG, Boylan JF, Cheng DC: The systemic inflammatory response to cardiac surgery: implications for the anesthesiologist. Anesthesiology 2002, 97(1):215-252.

53. van der Poll $\mathrm{T}$, Herwald $\mathrm{H}$ : The coagulation system and its function in early immune defense. Thromb Haemost 2014, 112(4):640-648.

54. Fergusson DA, Hebert PC, Mazer CD, Fremes S, MacAdams C, Murkin JM, Teoh K, Duke PC, Arellano R, Blajchman MA et al: A comparison of aprotinin and lysine analogues in high-risk cardiac surgery. The New England journal of medicine 2008, 358(22):2319-2331.

55. Asehnoune K, Dehoux M, Lecon-Malas V, Toueg ML, Gonieaux MH, Omnes L, Desmonts JM, Durand G, Philip I: Differential effects of aprotinin and tranexamic acid on endotoxin desensitization of blood cells induced by circulation through an isolated extracorporeal circuit. J Cardiothorac Vasc Anesth 2002, 16(4):447-451.

56. Wong BI, McLean RF, Fremes SE, Deemar KA, Harrington EM, Christakis GT, Goldman BS: Aprotinin and tranexamic acid for high transfusion risk cardiac surgery. The Annals of Thoracic Surgery 2000, 69(3):808-816. 
57. White N, Bayliss S, Moore D: Systematic review of interventions for minimizing perioperative blood transfusion for surgery for craniosynostosis. J Craniofac Surg 2015, 26(1):26-36.

58. Faraoni D, Goobie SM: The efficacy of antifibrinolytic drugs in children undergoing noncardiac surgery: a systematic review of the literature. Anesth Analg 2014, 118(3):628-636.

59. Faraoni D, Willems A, Melot C, De Hert S, Van der Linden P: Efficacy of tranexamic acid in paediatric cardiac surgery: a systematic review and metaanalysis. Eur J Cardiothorac Surg 2012, 42(5):781-786.

60. Eckert MJ, Wertin TM, Tyner SD, Nelson DW, Izenberg S, Martin MJ: Tranexamic acid administration to pediatric trauma patients in a combat setting: the pediatric trauma and tranexamic acid study (PED-TRAX). $J$ Trauma Acute Care Surg 2014, 77(6):852-858; discussion 858.

61. Beno S, Ackery AD, Callum J, Rizoli S: Tranexamic acid in pediatric trauma: why not? Crit Care 2014, 18(4):313.

62. Nishijima DK, Monuteaux MC, Faraoni D, Goobie SM, Lee L, Galante J, Holmes JF, Kuppermann N: Tranexamic Acid Use in United States Children's Hospitals. J Emerg Med 2016.

63. Horst J, Leonard JC, Vogel A, Jacobs R, Spinella PC: A survey of US and Canadian hospitals' paediatric massive transfusion protocol policies.

Transfusion medicine (Oxford, England) 2016, 26(1):49-56.

64. Patregnani JT, Borgman MA, Maegele M, Wade CE, Blackbourne LH, Spinella PC: Coagulopathy and shock on admission is associated with mortality for children with traumatic injuries at combat support hospitals. Pediatr Crit Care Med 2012, 13(3):273-277.

65. Baharoglu MI, Germans MR, Rinkel GJ, Algra A, Vermeulen M, van Gijn J, Roos YB: Antifibrinolytic therapy for aneurysmal subarachnoid haemorrhage. Cochrane Database Syst Rev 2013, 8:Cd001245.

66. Meretoja A, Churilov L, Campbell BC, Aviv RI, Yassi N, Barras C, Mitchell P, Yan B, Nandurkar H, Bladin $\mathrm{C}$ et al: The spot sign and tranexamic acid on preventing ICH growth--AUStralasia Trial (STOP-AUST): protocol of a phase II randomized, placebo-controlled, double-blind, multicenter trial. Int J Stroke 2014, 9(4):519-524.

67. Horrow JC, Hlavacek J, Strong MD, Collier W, Brodsky I, Goldman SM, Goel IP: Prophylactic tranexamic acid decreases bleeding after cardiac operations. J Thorac Cardiovasc Surg 1990, 99(1):70-74.

68. Horrow JC, Van Riper DF, Strong MD, Grunewald KE, Parmet JL: The doseresponse relationship of tranexamic acid. Anesthesiology 1995, 82(2):383-392.

69. Mitra B, Mazur S, Cameron PA, Bernard S, Burns B, Smith A, Rashford S, Fitzgerald M, Smith K, Gruen RL et al: Tranexamic acid for trauma: Filling the 'GAP' in evidence. Emergency Medicine Australasia 2014, 26(2):194-197.

70. Farrell NM, Wing HA, Burke PA, Huiras P: Addition of tranexamic acid to a traumatic injury massive transfusion protocol. Am J Health Syst Pharm 2015, 72(12):1059-1064. 
71. Maegele M: Coagulation factor concentrate-based therapy for remote damage control resuscitation (RDCR): a reasonable alternative? Transfusion 2016, 56 Suppl 2:S157-165.

72. Kelly JF, Ritenour AE, McLaughlin DF, Bagg KA, Apodaca AN, Mallak CT, Pearse L, Lawnick MM, Champion HR, Wade CE et al: Injury severity and causes of death from Operation Iraqi Freedom and Operation Enduring Freedom: 2003-2004 versus 2006. J Trauma 2008, 64(2 Suppl):S21-26; discussion S26-27.

73. Holcomb JB, McMullin NR, Pearse L, Caruso J, Wade CE, Oetjen-Gerdes L, Champion HR, Lawnick M, Farr W, Rodriguez S et al: Causes of death in U.S. Special Operations Forces in the global war on terrorism: 2001-2004. Ann Surg 2007, 245(6):986-991.

74. Paudyal P, Smith J, Robinson M, South A, Higginson I, Reuben A, Shaffee J, Black S, Logan S: Tranexamic acid in major trauma: implementation and evaluation across South West England. Eur J Emerg Med 2015.

75. Ausset S, Glassberg E, Nadler R, Sunde G, Cap AP, Hoffmann C, Plang S, Sailliol A: Tranexamic acid as part of remote damage-control resuscitation in the prehospital setting: A critical appraisal of the medical literature and available alternatives. J Trauma Acute Care Surg 2015, 78(6 Suppl 1):S70-75.

76. Vu EN, Schlamp RS, Wand RT, Kleine-Deters GA, Vu MP, Tallon JM: Prehospital use of tranexamic acid for hemorrhagic shock in primary and secondary air medical evacuation. Air Med J 2013, 32(5):289-292.

77. Mrochuk M, D OD, Chang E: Rural trauma patients cannot wait: tranexamic Acid administration by helicopter emergency medical services. Air Med J 2015, 34(1):37-39.

78. Lipsky AM, Abramovich A, Nadler R, Feinstein U, Shaked G, Kreiss Y, Glassberg E: Tranexamic acid in the prehospital setting: Israel Defense Forces' initial experience. Injury 2014, 45(1):66-70.

79. Rappold JF, Pusateri AE: Tranexamic acid in remote damage control resuscitation. Transfusion 2013, 53 Suppl 1:96S-99S.

80. Gonzalez E, Moore EE, Moore HB, Chapman MP, Chin TL, Ghasabyan A, Wohlauer MV, Barnett CC, Bensard DD, Biffl WL et al: Goal-directed Hemostatic Resuscitation of Trauma-induced Coagulopathy: A Pragmatic Randomized Clinical Trial Comparing a Viscoelastic Assay to Conventional Coagulation Assays. Ann Surg 2015.

81. Kobayashi L, Costantini TW, Coimbra R: Hypovolemic shock resuscitation. Surg Clin North Am 2012, 92(6):1403-1423.

82. Maegele M, Spinella PC, Schochl H: The acute coagulopathy of trauma: mechanisms and tools for risk stratification. Shock 2012, 38(5):450-458.

83. Lecker I, Wang DS, Romaschin AD, Peterson M, Mazer CD, Orser BA: Tranexamic acid concentrations associated with human seizures inhibit glycine receptors. The Journal of clinical investigation 2012, 122(12):46544666.

84. Hillman J, Fridriksson S, Nilsson O, Yu Z, Saveland H, Jakobsson KE: Immediate administration of tranexamic acid and reduced incidence of early 
rebleeding after aneurysmal subarachnoid hemorrhage: a prospective randomized study. Journal of neurosurgery 2002, 97(4):771-778.

85. Prehospital Tranexamic Acid Use for Traumatic Brain Injury. Available at: [https://clinicaltrials.gov/ct2/show/NCT01990768]. Accessed April 21, 2016. 


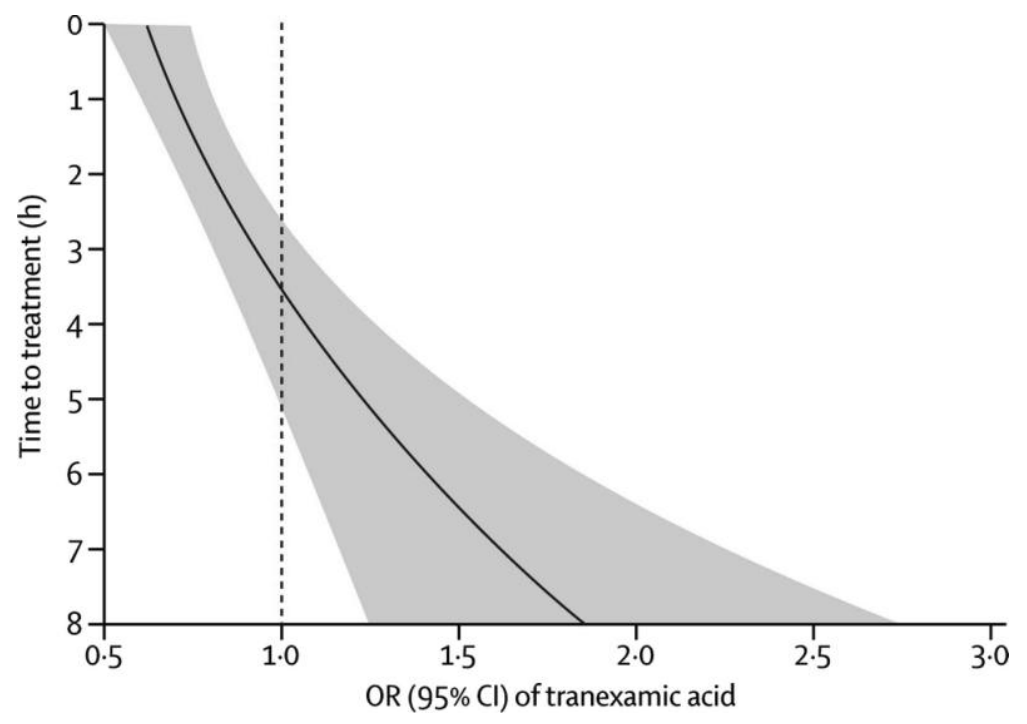




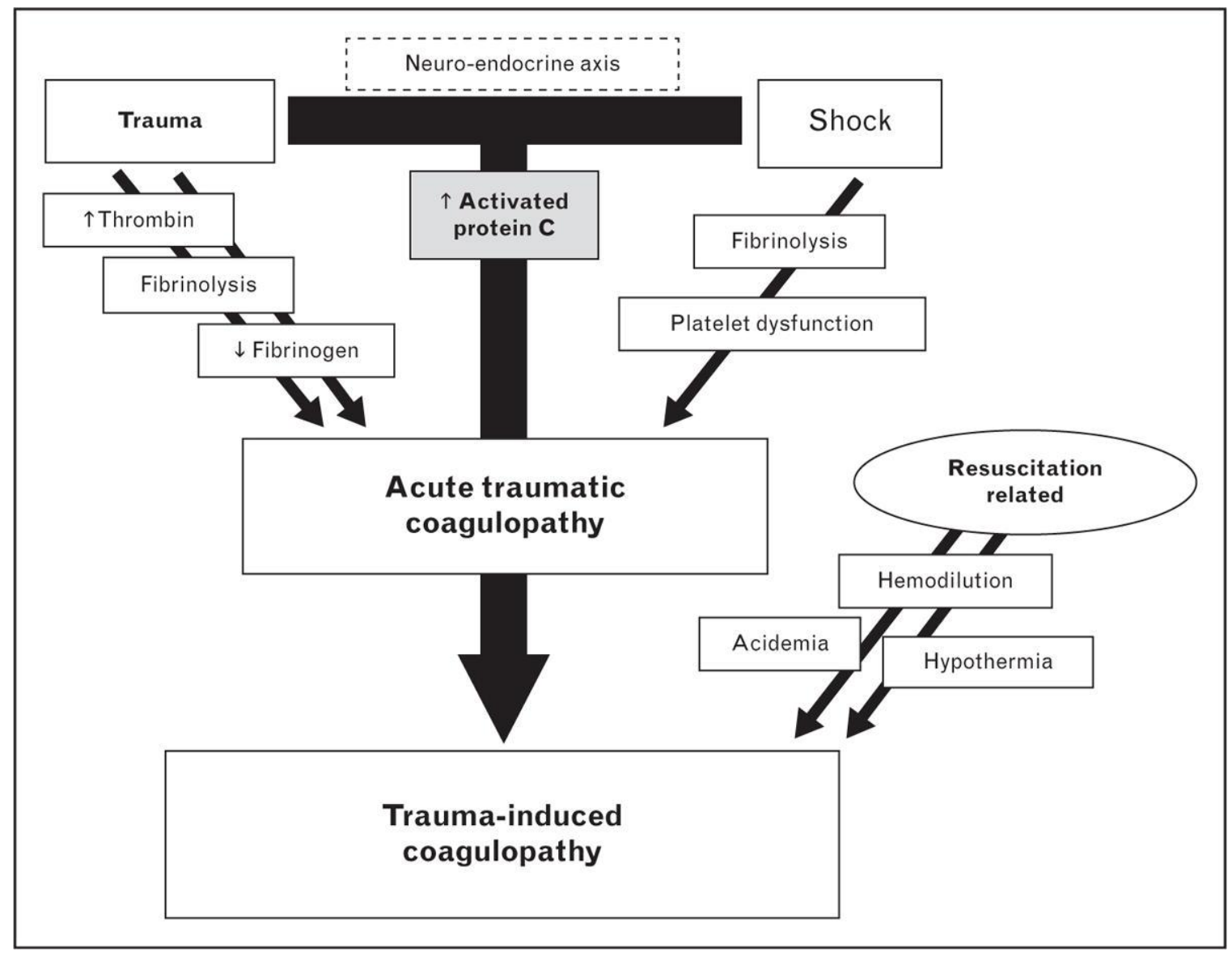




\begin{tabular}{|l|l|l|}
\hline \multicolumn{3}{|l|}{ Table 1 Dosing Regimens for Traumatic Hemorrhage } \\
\hline Study & Dose & Indication \\
\hline CRASH-2 [8] & $\begin{array}{l}1 \text { gram bolus followed by } \\
\text { a 1 gram infusion over } 8 \\
\text { hours }\end{array}$ & $\begin{array}{l}\text { Adult trauma patients with significant hemorrhage } \\
\text { (SBP }<90 \mathrm{~mm} \text { Hg or heart rate }>110 \text { bpm, or both), or } \\
\text { who were considered to be at risk of significant } \\
\text { hemorrhage, and who were within } 8 \mathrm{~h} \text { of injury }\end{array}$ \\
\hline MATTERs [7] & $\begin{array}{l}\text { 1 gram bolus repeated at } \\
\text { discretion of treating } \\
\text { surgeon }\end{array}$ & $\begin{array}{l}\text { Patients who received at least 1 unit of PRBCs within } \\
\text { 24 hours of admission following combat related injury }\end{array}$ \\
\hline TAMPITI [13] & $\begin{array}{l}\text { *Ongoing trial: one time } \\
\text { bolus of 2 or 4 grams }\end{array}$ & $\begin{array}{l}\text { Adult trauma patients ordered to receive at least 1 } \\
\text { blood product and/or immediate transfer to operating } \\
\text { room to control bleeding, and within 2 hours of injury }\end{array}$ \\
\hline STAAMP [12] & $\begin{array}{l}\text { *Ongoing trial: one time } \\
\text { bolus of 1 gram } \\
\text { prehospital dose }\end{array}$ & $\begin{array}{l}\text { Adult trauma patients being transported via air } \\
\text { medical services from scene or referring hospital, with } \\
\text { SBP }<90 \text { mm Hg or heart rate }>110 \text { bpm, and within 2 } \\
\text { hours of injury }\end{array}$ \\
\hline PATCH [69] & $\begin{array}{l}\text { *Ongoing trial: 1 gram } \\
\text { prehospital bolus } \\
\text { followed by 1 gram in- } \\
\text { hospital infusion over 8 } \\
\text { hours }\end{array}$ & $\begin{array}{l}\text { Adult trauma patients being transported to a trauma } \\
\text { center with a coagulopathy of severe trauma (COAST) } \\
\text { score of 3 or greater, and within 3 hours of injury }\end{array}$ \\
\hline
\end{tabular}

